\title{
Una política «a medio camino». Reflexiones sobre la política para pueblos indígenas de contacto reciente en Brasil
}

\section{Clarisse Jabur}

iD https://orcid.org/0000-0001-5220-3350

Departamento de Antropología, Universidad de Brasilia, Brasil jabur.clarisse@gmail.com

RESUMEN

La politica para los pueblos indígenas de reciente contacto - PIRC en Brasil está en construcción. Aunque las directrices para los periodos posteriores al contacto estuvieron presentes en otros momentos de la politica gubernamental, no libraron a los pueblos indígenas de destinos crueles como las masacres, las epidemias y el exterminio total. Solo tras el cambio de politica en 1987 se incluyeron medidas sanitarias en las acciones posteriores al contacto y otras acciones con un sesgo educativo. En los últimos años, se han producido algunos avances en las normas internas relacionadas con diversas politicas públicas, destacando la publicación de la ordenanza conjunta MS/ FUNAI $N^{\circ} 4.094$ sobre la atención a la salud de los pueblos indígenas de contacto reciente. Asimismo, se han formulado los primeros Planes de Gestión Territorial y Ambiental - PGTA por pueblos indígenas de reciente contacto en Brasil. Esta política está todavía «a medio camino»y tiene algunos retos que consolidar.

Palabras clave: política indigenista, pueblos indigenas de reciente contacto, pueblos indígenas aislados, Brasil, derechos indígenas. 


\title{
Uma política no «meio do caminho»: reflexões sobre a política para Povos Indígenas de Recente Contato no Brasil
}

\author{
RESUMO
}

A política para Povos Indígenas de Recente Contato - PIRC no Brasil está em construção. Apesar das diretrizes para os periodos pós-contato estarem presentes em outros momentos na política governamental, não livraram os povos indigenas de destinos cruéis como massacres, epidemias e extermínios completos. Apenas após a mudança da política em 1987, foram incluídas medidas sanitárias nas ações pós-contato e outras ações com viés educativo. Nos últimos anos ocorreram alguns avanços em normativas internas relacionadas a diversas políticas públicas, com destaque para a publicação da Portaria Conjunta MS/ FUNAI $n^{\circ} 4.094$ acerca da atenção à saúde para os povos indígenas de recente contato. Da mesma maneira, foram formulados os primeiros Planos de Gestão Territorial e Ambiental - PGTAs por povos indigenas de recente contato no Brasil. Essa política encontra-se no «meio do caminho» e possui alguns desafios para se consolidar.

Palavras-chave: Política indigenista; povos indigenas de recente contato; povos indigenas isolados; Brasil; direitos indigenas.

\section{A «halfway» policy. Reflections on the policy for Indigenous Peoples of Recent Contact in Brazil}

\section{ABSTRACT}

The policy for indigenous peoples of recent contact (PIRC) in Brazil is under construction. Although the guidelines for post-contact periods were present at other moments in government policy, they did not free indigenous peoples from cruel fates such as massacres, epidemics, and total extermination. Only after the policy change in 1987 were health measures included in post-contact actions and other actions with an educational bias. In recent years, there have been some advances in internal regulations related to various public policies, highlighting the publication of joint ordinance MS / FUNAI No. 4.094 on health care for indigenous peoples of recent contact. Likewise, the first Territorial 
and Environmental Management Plans (PGTA) have been formulated by indigenous peoples of recent contact in Brazil. This policy is still "half way» and has some challenges to consolidate.

Keywords: indigenous politics, indigenous peoples of recent contact, isolated indigenous peoples, Brazil, indigenous rights.

\section{ANTECEDENTES DE LA POLÍTICA DE PUEBLOS INDÍGENAS DE CONTACTO RECIENTE EN BRASIL}

La política de pueblos indígenas en contacto reciente (PIRC, por sus siglas en portugués) es poco conocida, en comparación con la política de pueblos indígenas aislados, en la cual Brasil es protagonista en las metodologías de protección. La política del PIRC aún está en construcción y tiene desafíos por consolidar. En este artículo pretendemos presentar un panorama crítico de la construcción y ejecución de esta política, señalando además sus desafíos inherentes.

En primer lugar, es necesario señalar que las directrices que guiaron las acciones en los periodos posteriores al contacto con los pueblos indígenas existieron en otros momentos de la política gubernamental. Sin embargo, estas acciones no liberaron a los pueblos indígenas de destinos crueles, como masacres, epidemias y exterminios directos. En realidad, muchas veces fueron estas mismas acciones las que desencadenaron procesos de etnocidio y genocidio de cientos de personas, proyectando consecuencias que perduran en el tiempo.

Durante el trabajo del Servicio de Protección Indígena - SPI, las pautas posteriores al contacto se limitaron a «pacificar» a los pueblos indígenas, obligándolos a una nueva forma de vida a través de actividades educativas, cívicas y labores agrícolas (Lima, 1995). El documento Normas sociológicas para o aproveitamento do índio, elaborado por el mariscal Cândido Rondon, describe el ciclo de la pacificación del SPI. Según él, los indígenas debían volverse sedentarios y depender de nuevos objetos, principalmente los de uso agrícola (machetes, hachas, etc.), y los que anunciaban un carácter civilizador, como la ropa. Estas nuevas necesidades, según el pensamiento positivista vigente en ese momento ${ }^{1}$, llevarían a los pueblos indígenas a trabajar para obtenerlas (Magalhães, 1943).

El positivismo prevaleció en el pensamiento indigenista de la época. Se concibió que los indígenas se encontraban en una etapa transitoria y que debían evolucionar hasta integrarse a la comunidad nacional con los «brasileños». 
En 1967, con la creación de la Fundación Nacional del Indio - FUNAI, se hicieron algunos cambios a las pautas de acción para los periodos posteriores al contacto. Luego, en 1973, se publicó el Estatuto del Indio, Ley N ${ }^{\circ} 6.001$ (Brasil, 1973), que todavía consideraba la transitoriedad de los pueblos indígenas ${ }^{2}$. En otras palabras, la «condición indígena» debí ser superada. Fue un proceso inevitable. Así, los pueblos indígenas fueron categorizados según su «grado de integración», es decir, «aislados», «en proceso de integración» e «integrados» (artículo 4). La categoría de «contacto reciente» aún no estaba presente.

En las décadas de 1970 y 1980, fuimos testigos de un impulso en proyectos económicos como carreteras, centrales hidroeléctricas, represas, proyectos mineros a gran escala, entre otros. Y con eso, también se intensificaron los procesos de contacto con grupos indígenas aislados. Habitualmente contactados de manera forzada por los antiguos Frentes de Atracción y Contacto, los pueblos fueron sacados de sus territorios para dar lugar a los emprendimientos (Valente, 2017; Ribeiro, 1996 [1970]; Davis, 1978).

Hubo prisa por hacer contacto, ya que las obras avanzaban rápidamente. La ruta de las máquinas pasaría prácticamente por algunos pueblos. Estos llegarían de todos modos, tanto si el contacto estaba consolidado como si no. Se preguntó a los equipos sobre los plazos para hacer contactos y, muchas veces, la falta de recursos materiales y humanos hizo que actuaran de manera precaria y con diversas improvisaciones (Valente, 2017). Parte del testimonio del sertanista Francisco Meirelles reveló que «no veía otra salida que realizar atracciones y pacificación financiadas por caucheros y promover el desplazamiento de los indígenas fuera de las áreas de interés económico del estado» (Freire, 2008, p. 111).

Las acciones posteriores al contacto en ese momento no incluían acciones sanitarias eficientes para los indígenas. En muchas situaciones, se les dejó a su suerte. La mortalidad tras el contacto era un hecho dado, considerado una condición irreversible e irremediable, un mero efecto de cualquier contacto. Como consecuencia de cualquier acción de atracción «es normal que muera el 50\% de un grupo en contacto» (Freire, 2008, p. 111). En Matos et al. se consolida una serie de testimonios de los sertanistas ${ }^{3}$ sobre las tragedias poscontacto derivadas de las enfermedades (2021, pp. 140-142).

\footnotetext{
2 Según el artículo $1^{\circ}$ del Estatuto do Indio: «Esta ley regula la condición jurídica de los indígenas o selvícolas y de las comunidades indígenas, con el propósito de preservar su cultura e integrarlos, progresiva y armoniosamente, en la comunidad nacional».

3 Agentes del FUNAI que trabajan en campo en los Frentes de Protección Etnoambiental.
} 
Las consecuencias de las epidemias fueron más duraderas que la propia enfermedad. Siendo estas poblaciones dependientes en modo exclusivo de los recursos naturales, el impedimento para la ejecución de las acciones cotidianas ha provocado el colapso de algunas sociedades por falta de agua, fuego y alimentos, principalmente. «Con toda la gente enferma del pueblo, no hay nadie que pueda cuidar los campos, dar comida y agua» (Rodrigues, 2021, p. 41). Muchas otras sociedades sufrieron el impacto en el «equilibrio psíquico colectivo», teniendo como consecuencias fenómenos calificados por Cueva como desesperación, «muerte por tristeza» o «por dejar morir» (Cueva, 2007, p. 92).

En 1987, se produjeron cambios importantes en la política de protección de los pueblos indígenas aislados, alterando las formas en que el organismo indígena concebía y manejaba el proceso de contacto (Freire, 2008). En el I Encuentro de Sertanistas, se establecieron nuevos lineamientos para la acción del Estado brasileño con los pueblos indígenas aislados, definiendo que la premisa de protección para estos pueblos indígenas sería la del «no contacto». También fue creado el Sistema de Protección a los Indígenas Aislados (SPI, por sus siglas en portugués) (Santos y Mendes, 2007; Opi, 2020a; Amorim, 2016; FUNAI, 1987).

Entre las trece conclusiones de la reunión presentadas a Romero Jucá, entonces presidente de FUNAI, la principal fue que «contactar es dañino para los indígenas». Por lo tanto, solo debe ocurrir cuando exista riesgo de supervivencia de pueblos aislados (FUNAI, 1987). Es decir, los propios sertanistas, cansados de presenciar la muerte de grupos enteros, principalmente por enfermedades, enfatizaron que lo que protegería a los indígenas no sería el contacto y sí otro tipo de política que respetase la autonomía y la libre elección de los aislados ${ }^{4}$. Aun así, el contacto está previsto en uno de los tres subsistemas que compone el SPI, pero solo en condiciones que pongan en riesgo la vida de los indígenas aislados.

La priorización de las acciones de salud poscontacto es uno de los principales puntos de avance de la política. Primero, se reconoció que la situación de contacto en sí es de alto riesgo y peligro para los pueblos indígenas recién contactados debido al contagio de enfermedades infecciosas y contagiosas. En el momento del encuentro, se plantearon algunas medidas para aplicar durante este período: «establecer un plan de salud con anticipación, crear una infraestructura mínima de atención; enviar recursos humanos y materiales con prontitud y rapidez, y

Así, hoy, una de las principales atribuciones del organismo indigenista es «garantizar a los pueblos indígenas aislados el ejercicio de su libertad y sus actividades tradicionales sin la obligación de contactarlos» (Brasil, 2017; ACNUDH, 2012). 
ayudarlos con la alimentación» (FUNAI, 1987). La nueva política, en parte, reformula los lineamientos con respecto a los llamados pueblos recién contactados, no solo con respecto a los aislados. Así, a diferencia del momento anterior, las pautas de pacificación son reemplazadas por la búsqueda de la autosuficiencia y por procesos educativos no paternalistas (para usar los términos de la época).

Pocos pueblos fueron contactados por iniciativas de la FUNAI después de 1987, como los akuntsu y kanoê en 1995 (Valadão, 1996; Tavares, 2020), un grupo korubo en 1996 (Vargas da Silva, 2017), uno de los grupos arara en 1987 y algunos grupos awá en 1989, 1998 y 2000 (García, 2010)․ Estos pueblos fueron llamados referencias de indios aislados durante un cierto período hasta que fueron reconocidos como referencias recién contactadas ${ }^{6}$ (Vaz, 2011, pp. 31-32). Destacamos que, a pesar de que en los últimos casos mencionados el contacto fue provocado por FUNAI, el tipo de asistencia que recibió cada pueblo fue diferente, probablemente influenciado por criterios técnicos, lineamientos de gestión, contexto político, entre otros factores. Podemos enumerar que los akuntsu, kanoê, korubo, zo'é y suruwaha ${ }^{7}$ recibieron asistencia específica de equipos de los Frentes de Protección Etnoambiental - FPE, unidades específicas de la FUNAI vinculadas al Departamento de Indígenas Aislados - DII ${ }^{8}$.

Sin embargo, algunos grupos como los awá, arara y yanomami, que ahora se consideran de contacto reciente y que fueron contactados por la FUNAI, tenían una forma específica de asistencia que finalmente fue abandonada. Posteriormente, de manera no estandarizada, fueron asistidos de manera no específica por equipos vinculados con las administraciones regionales (luego por las coordinaciones regionales) de FUNAI, generalmente por jefes de los puestos. Había cierta autonomía en el trabajo de las administraciones regionales, donde cada una actuaba a su manera, sin pautas homogéneas. En el nivel central, en FUNAI en Brasilia, la asignación relacionada con PIRC pasó por diferentes órganos administrativos,

5 «Toda la historia del contacto Awá-Guajá se basa en contactos ocasionales con pequeños grupos y no con toda una población. Y, como era de esperar, siempre hay grupos que se permiten contactarse o incluso buscar el contacto, sobre todo, por motivos de salud, alimentación y otras presiones, y otros que se niegan al contacto» (García, 2019, p. 111).

6 En la lista presentada por Vaz (2011, pp. 31-32), hay siete referencias recientemente contactadas: korubo, so'é, akuntsu, kanoê, piripkura, awá y suruwaha.

7 El servicio a los suruwaha fue asumido por el ex DII, siguiendo la recomendación del Ministerio Público Federal (PRDC / AM N ${ }^{\circ}$ 003/2003), que también indicó la remoción de todas las misiones religiosas de los indígenas suruwaha. Tierra (Vaz, 2008).

8 El DII dio origen a la actual CGIIRC, de la que hablaremos más adelante. 
como la Directoría de Asistencia, por ejemplo. La configuración actual surge de la «reestructuración» de FUNAI que se llevó a cabo en 2010.

Así, de acuerdo con el Reglamento FUNAI vigente, artículo 204, la Coordinación de Políticas para pueblos indígenas aislados y de reciente contacto - COPIRC (subordinada a la Coordinación General de Indígenas Aislados y de reciente contacto - CGIIRC tiene la atribución de, entre otras, «coordinar el desarrollo de lineamientos de políticas orientadas a proteger y promover los derechos de los pueblos indígenas de reciente contacto» y «apoyar la implementación de políticas sociales universales, junto a los pueblos indígenas de contacto reciente, intersectorial e interinstitucionalmente» (FUNAI, 2017).

El régimen actual también denota una apertura a la intersectorialidad interna. Numerosas coordinaciones de la FUNAI tienen interfaz con COPIRC y CGIIRC, y existe un flujo constante de acciones como control del ingreso a tierras indígenas, monitoreo de acciones de salud, orientación de acciones de diálogo con pueblos indígenas de reciente contacto, monitoreo de la implementación de protocolos de consulta previa e informada, entre otros (FUNAI, 2017).

COPIRC / CGIIRC puede verse como una especie de intermediario de procesos relacionados con PIRC, a través de los cuales pasan diversos flujos administrativos. Es la COPIRC que, en dos movimientos, internaliza las discusiones y reflexiones sobre la política del PIRC para los distintos sectores de FUNAI, y exterioriza parámetros y lineamientos a seguir por los organismos públicos que tienen el rol estatutario de actuar con el PIRC.

Durante este período, hubo un aumento importante en el número de unidades descentralizadas vinculadas al CGIIRC para atender al PIRC, de seis a doce

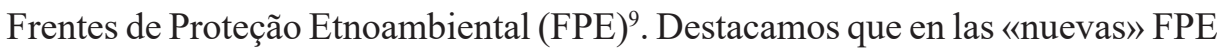
(FPE Awá, FPE Yanomami y Ye'kuana y FPE Médio Xingu) se reincorporan los PIRC, que estaban siendo atendidos de manera no específica mencionados anteriormente, es decir, los awá, yanomami, arara (TI Cachoeira Seca), araweté y parakanã (TI Apyterewa). Varios grupos se quedaron sin asistencia específica hasta que se definió una política más clara.

9 Actualmente hay once FPE operando en Brasil (FUNAI, 2021). 


\section{LA CATEGORIZACIÓN ADMINISTRATIVA DE LOS PUEBLOS INDÍGENAS DE CONTACTO RECIENTE}

La categoría administrativa aislado fue la única en el Estatuto Indio (Brasil, 1973) que se mantuvo en la estructura actual de la política indigenista, modificándose gradualmente en medio de los procesos de reestructuración de la FUNAI, hasta acercarse al concepto presentado en directrices internacionales. Es decir, hoy solo hay pueblos indígenas aislados y los demás, es decir, los pueblos indígenas de contactados. En otras palabras, la categoría de pueblos indígenas de contacto reciente no estaba presente en el Estatuto do Índio.

Sin embargo, a pesar de los cambios de política desde 1987, Forline y Pozzobon (2006, p. 542) critican el concepto de aislados utilizado por la FUNAI en 2002, ya que seguía centrándose en el desconocimiento de una cierta «distancia cultural» como elementos para caracterizarlos. Es decir, la distancia geográfica y cultural, y el desconocimiento del Estado sobre ellos es lo que los categoriza como aislados. Según los autores, el Estado caracteriza a esos pueblos como si vivieran de la misma manera que hace quinientos años. Se desconoce que varios pueblos se vieron obligados a «aislarse» y sufrir un cambio en sus formas de vida. El concepto adoptado hoy por la FUNAI para los pueblos indígenas aislados enfatiza la autosuficiencia de estos pueblos y la evitación de las relaciones (FUNAI, 2018). La discusión sobre el concepto de aislamientos es un «campo minado» donde hay connotaciones políticas difusas y diferentes matices de análisis. Coincidimos plenamente con Amorim (2018) en la discusión del término voluntario:

según la normativa vigente, el derecho a la autodeterminación y a desarrollar sus estrategias de vida debe estar totalmente desconectado de las razones y elementos que subyacen a tales decisiones. Independientemente de las motivaciones, voluntarias o no, lo que hay que reconocer es la propia decisión. Después de todo, en la mayoría de los casos, tales motivaciones son solo hipótesis y especulaciones (Amorim, 2018, p. 192).

Son varios los desafíos metodológicos y políticos que surgen de la discusión sobre el «aislamiento» que ya han sido abordados por otros autores y que no abordaremos aquí. Sin embargo, es necesario señalar que la categoría de contacto reciente está estrechamente vinculada con la categoría de aislados. Primero, porque existe una línea muy fina (administrativamente hablando) entre los dos, ya que un pueblo indígena puede rápidamente llegar a ser considerado un contacto reciente después de pasar años —o incluso décadas - siendo considerado aislado. Esta decisión la toma el Estado, con base en el evento del contacto oficial. 
Tenemos que partir de la premisa de que estos pueblos se consideran aislados solo desde la perspectiva de la sociedad nacional, del Estado, ya que estos grupos forman parte de redes complejas y amplias y ciertamente tenían varios tipos de relaciones directas o indirectas antes de este contacto llamado oficial. Si bien el Estado considera que el contacto comienza solo en la fecha en que se produce un encuentro pacífico entre los indígenas y sus agentes, esta relación se ha prolongado por mucho más tiempo.

El momento de contacto dicho como oficial es solo una continuación de sus procesos de relación con esta amplia red de relaciones. Es necesario resaltar que la historia de estos pueblos no comienza con el contacto, es decir, cuando se convierten en «apéndices del Estado Nacional» (Viveiros de Castro, 1999, p. 167). Como dijo Gallois, «los Zo'é, como cualquier otro grupo, no estaban ni nunca estuvieron aislados; tenían un historial de contactos enorme y complejo» (Gallois, 2013, p. 110). El contacto es un proceso que tiene distintas connotaciones, tanto para los indígenas como para el Estado, y las consecuencias de esta próxima relación siempre serán únicas. Es fundamental, siempre que sea posible, incluir las percepciones indígenas en el análisis de los procesos de contacto. Coincidimos con Reis y Albertoni (2017) cuando afirman que «para afrontar los hechos de contacto y sus consecuencias, no basta con concebirlos como un tránsito de una etapa a otra, sin tener en cuenta los diversos factores y contextos que la impregnar esos momentos» (Reis y Albertoni, 2017, p. 815).

Volviendo a la discusión de la interacción de las categorías de pueblos indígenas de contacto reciente y pueblos indigenas aislados, quienes trabajan el tema en la práctica deben enfrentar la confusión diaria entre los dos términos en algunos discursos de representantes gubernamentales e indígenas, no siempre los que tienen alguna relación con el PIRC. Por lo tanto, no hay forma de separar totalmente la categoría de pueblos indígenas de contacto reciente con la de pueblos indígenas aislados ${ }^{10}$.

Sin embargo, vemos la categoría de PIRC bastante difusa, ya que lleva un conjunto semántico más nebuloso. Intentaremos hacer algunos comentarios sobre las dos definiciones diferentes que se encuentran en los documentos gubernamentales para la categoría de pueblos indígenas de contacto reciente. Uno de ellos está expuesto en el Plan Plurianual (de 2012 a 2015) y en la web de FUNAI.

10 Hay otras relaciones interesantes por explorar, pero lo dejamos para análisis futuros, como la participación de los PIRC en procesos de discusión, planificación y contacto con grupos aislados (como el proceso de contacto con el último grupo korubo que tuvo lugar en 2019). 
aquellos grupos (pueblos o fragmentos de pueblos) que mantienen relaciones de contacto permanente y/o intermitente con segmentos de la sociedad nacional y que, independientemente del momento de contacto, presentan singularidades en su relación con la sociedad nacional y selectividad (autonomía) en la incorporación de bienes y servicios. Son, por tanto, grupos que mantienen fortalecidas sus formas de organización social y sus propias dinámicas colectivas, y que definen su relación con el Estado y la sociedad nacional con un alto grado de autonomía (FUNAI, 2021).

Los dos términos que componen la categoría administrativa de contacto reciente están cargados semánticamente. La primera cuestión que se destaca es que el término reciente se asocia con una consideración de «independientemente del tiempo de contacto». En otras palabras, no es a través del criterio temporal que estas personas se clasificarán como de contacto reciente. De ahí otra interpretación común que conecta el aspecto temporal con los grados de contacto, como en la lógica de la escala evolutiva establecida por el Estatuto indio de distante/primitivo/aislado - recién contactados/contacto reciente - contactado/ evolucionado/civilizado.

Durante un tiempo, notamos una cierta falta de estandarización en las regulaciones de la FUNAI entre los términos contactados recientemente y contacto reciente ${ }^{11}$. ¿Son sinónimos? Al parecer, el primer término presenta una actitud de pasividad de un determinado pueblo indígena con relación al proceso de contacto. Es decir, el pueblo tal ya fue contactado. Contacto reciente sería un término más apropiado para referirse a los pueblos indígenas que han establecido contacto.

La otra definición de PIRC se encuentra en el artículo 2 de la Portaria Conjunta do Ministério da Saúde de la FUNAI N 4.094, de 20 de diciembre de 2018, que abordaremos con mayor profundidad más adelante.

pueblos o grupos indígenas que mantienen relaciones de contacto ocasional, intermitente o permanente con segmentos de la sociedad nacional, con poco conocimiento de los códigos o incorporación de los usos y costumbres de la sociedad circundante, y que mantienen una importante autonomía sociocultural (FUNAI / MS, 2019).

Aquí vemos una versión más resumida de la categoría administrativa PIRC, con algunos aspectos en común con la primera definición: (i) «conocimiento reducido de códigos o incorporación de los usos y costumbres de la sociedad

11 En el Reglamento de la FUNAI de 2012 (FUNAI, 2012), el artículo 192 se refiere a recién contactados y el artículo 197 a contactos recientes, por ejemplo. 
circundante», y (ii) «que conservan significantes socioculturales autonomía» (FUNAI / MS, 2019).

El hecho es que estas dos características generan algunas representaciones imprecisas sobre la categoría de PIRC. Las más comunes son la asociación del término contacto reciente con «imágenes de fragilidad, inocencia y marginalidad» que «condicionan las relaciones que históricamente nuestra sociedad mantiene con estos grupos» (Gallois, 1994, p. 121). Son imágenes que también rememoran al indígena hiper real, «dependiente, sufrido, víctima del sistema [...] íntegro en sus acciones e intenciones y preferentemente exótico» (Ramos, 1995, p. 7).

Pretendemos considerar que los PIRC, a pesar de ser pueblos con historias de contacto, características culturales y sociales muy diversas, tienen en común la configuración de la relación que establecen con los ámbitos del Estado nacional. Suelen tener interlocución únicamente con equipos de FUNAI y la Secretaría Especial de Salud Indígena - SESAI y acceden a muy pocos servicios públicos, en general, aquellos relacionados con la salud. Y sus formas de «comunicación» con el Estado brasileño se realizan a menudo a través de manifestaciones a la manera de los indígenas «hiper-reales» (Ramos, 1995).

Finalmente, creemos que la existencia de las categorías administrativas de pueblos indígenas aislados y pueblos indígenas de contacto reciente es necesaria para garantizar recursos financieros y humanos específicos para llevar a cabo el trabajo de protección y promoción de sus derechos. Es importante discutir estos conceptos, siempre que no «vacíen», por así decirlo, las categorías hasta el punto de perjudicar la promoción y ejecución de políticas específicas para estos pueblos.

\section{PERO, DESPUÉS DE TODO, ¿CUÁLES SON LOS PUEBLOS INDÍGENAS DE RECIENTE CONTACTO EN BRASIL?}

Los complejos cuestionamientos relacionados con la categoría generan cierta falta de claridad sobre cuáles son los PIRC en Brasil. En algunos casos, el tiempo de contacto los caracteriza (aunque no es un aspecto vinculante del concepto), como en las situaciones de nuevos contactos que tuvieron lugar en 2014, 2015 y 2019. Otros pueblos fueron incluidos en esta categoría en circunstancias diferentes, unas veces por decisiones políticas y otras por criterios técnicos.

Según el sitio web de FUNAI, «actualmente FUNAI coordina y apoya acciones de protección y promoción en 19 tierras indígenas habitadas por grupos indígenas de reciente contacto, como los Zo'é, Awá Guajá, Avá Canoeiro, 
Akun'tsu, Canôe, Piripkura, Arara de TI Cachoeira Seca, Araweté, Suruwahá y Yanomami, entre otros» (FUNAI, 2021).

En otras palabras, no especifica otros pueblos, como los waimiri-atroari, para los cuales incluso existe un FPE para su asistencia. También se puede ver una especificación del grupo arara de TI Cachoeira Seca y no la de TI Arara, un grupo previamente contactado. Tampoco hay presencia de otros PIRC asistidos por las coordinaciones regionales de FUNAI. Al final, esta lista pública en el sitio web de FUNAI queda abierta cuando coloca «entre otros».

En el documento 27 (Relatoría del Taller «Directrices de atención a pueblos indígenas de contacto reciente: nuevas experiencias, viejos desafíos» de la FUNAI) adjunto al Reclamo por Incumplimiento del Precepto Fundamental ADPF $N^{\circ} 709$, son citados «al menos 18 pueblos indígenas de reciente contacto».

Los PIRC atendidos por los Frentes de Protección Etnoambiental - FPE enumerados son: akunt'su, arara, araweté, awá-guajá, kanoê, korubo, parakanã, piripkura, personas de contacto reciente xinane, suruwaha, yanomami, waimiri atroari y zo'é. Notamos la ausencia de mención del pueblo tsohom-djapa, quienes también son mencionados en el informe del taller mencionado. Otros PIRC asistidos directamente por las coordinaciones regionales antes mencionadas son avá-canoeiro (de TI Avá-Canoeiro), pirahã, juma, hupdä’h y yuhupdeh, enawene-nawê.

Cuando añadimos otros temas, como la autodeterminación, la categoría administrativa se vuelve aún más compleja. ¿Es responsabilidad de la agencia indigenista «identificar» $\mathrm{o}$ «reconocer» a los pueblos indígenas como un contacto reciente? ¿Cómo pueden los indígenas participar activamente en la construcción de esta categoría y consecuentemente en la política misma? Son cuestiones que no estamos en condiciones de definir en este momento, pero que merecen una reflexión continua.

\section{NUEVOS CONTACTOS}

Inusualmente, luego de casi dieciocho años sin el establecimiento de procesos de contacto por iniciativa de FUNAI, ocurrieron cuatro situaciones en solo dos años (2014 y 2015): en junio de 2014, con el pueblo xinane (FUNAI, 2014a; Gil, 2019); con dos grupos korubo en octubre de 2014 y septiembre de 2015 (FUNAI, 2014b, FUNAI, 2015a; Amorim, 2014; Vargas da Silva, 2017), y un grupo awá en diciembre de 2014 (FUNAI, 2014c; Otto, 2017; García, 2019). Casi proféticamente, algunos se preguntaron si no estaríamos en la «década de los contactos» (Shepard, 2016). 
Estos fueron procesos de contacto emprendidos por los propios indígenas (en aislamiento) con otros pueblos indígenas que ya habían sido contactados. FUNAI y SESAI llegaron en un momento posterior a los primeros encuentros, iniciando una serie de acciones poscontacto, principalmente relacionadas con la salud y la recopilación de información. En todos los grupos que hicieron contacto hubo individuos debilitados y / o con remanentes de problemas de salud (Reis y Albertoni, 2017, p. 820), y que denunciaron situaciones de violencia y agresión previas.

Es difícil pensar en la propia voluntad como inherente a la condición de aislamiento conociendo los relatos de estos pueblos. ¿Fueron estos contactos voluntarios? ¿El objetivo era solo establecer nuevas relaciones o prácticamente se rindieron por otras razones? Informaremos rápidamente sobre la situación de la gente xinane y el grupo awá para reflexionar sobre estos temas.

En el caso del Pueblo de Xinane, coincidimos con Gil (2019) en que, «para entender las motivaciones que llevaron a los jóvenes del Pueblo de Xinane a acercarse ese día, debemos considerar las circunstancias de esa región e, igualmente, las condiciones creadas por su invasión por brasileños y peruanos durante más de un siglo» (Gil, 2019, p. 166). Según los relatos de los indígenas, en momentos anteriores tuvieron relaciones más o menos duraderas con personas no-indígenas. Las marcas de esta relación estaban en la piel, como lo expresan las cicatrices de bala en la espalda de uno de los individuos. Además, el grupo portaba una serie de objetos (Meirelles, 2017) que denotaban estas relaciones pasadas.

El grupo sumaba solo 34 personas cuando llegó en junio de 2014. Según Rodrigues (2020):

No había ancianos y el número de niños menores de cinco años era pequeño. También cabe destacar el reducido número de mujeres. Según los relatos de esos indígenas $[\ldots]$ el grupo venía huyendo durante mucho tiempo de los ataques de personas no indígenas, posiblemente del lado peruano, donde hay tala ilegal y presencia de narcotraficantes [...]. En cuanto a enfermedades, mencionaron muertes por fiebre, tos, diarrea y vómitos. Ninguno de los adultos aparentemente tenía padres vivos. Un grupo de sobrevivientes, extremadamente vulnerables, que requerían una atención especial de forma continua para no extinguirse (p. 44).

La hipótesis de Gil es que, aun con los riesgos que conlleva el contacto, los jóvenes decidieron entablar nuevas relaciones, abriéndose al mundo exterior para hacer posible su existencia. El contacto también permitiría «oportunidades de alianza matrimonial» (Gil, 2019, p. 169), ya que no existían al interior de su grupo. 
El grupo awá, que llegó a Terra Indígena Caru (MA), estaba aún más debilitado. Compuesto por dos mujeres y un joven, presentaban inanición severa y posteriormente se descubrió que también tenían tuberculosis (Reis y Albertoni, 2017, p. 815; García, 2019). El joven, pocos días después del contacto, se casó con una awá de la aldea de Tiracambu, lo que debió ayudar en su adaptación. Sin embargo, las mujeres sufrieron mucho, ya que tuvieron que pasar unos meses en la ciudad de São Luis (MA) para el tratamiento de la tuberculosis. No podían alimentarse con alimentos que no formaban parte de su dieta, como farinha, por ejemplo. Según sus relatos, en el bosque se alimentaban prácticamente solo de mesocarpio de babasú y otros pocos tipos de alimentos. Pensaban que el pueblo era muy ruidoso y los animales que criaban eran fastidiosos, lo que provocaba un malestar visible. Así, las mujeres planearon su «fuga» y en 2017 regresaron al monte.

Según el análisis de Otto, los awá sabían que se iban a ir y dieron su consentimiento, "porque cuando las mujeres awá-té expresaron su deseo de volver a vivir solas en el bosque, acordaron dejarlas ir [...] Las dejaron en paz, las dejaron ir...» (Otto, 2017, p. 98).

Una de las mujeres murió poco después de salir de la aldea. Según los relatos recogidos por la lingüista Marina Magalhães de los awá de la aldea de Tiracambu, poco después de la muerte de la mujer, llegaron leñadores disparando contra todo, incluido el cuerpo de Marjuá ${ }^{12}$ (Magalhães y Maxikôa, 2017). La otra mujer logró escapar y se perdió en el bosque. Trágicamente, «la quema destruyó gran parte del bosque, y ella perdió la referencia a los caminos» (op. cit.). La mujer fue encontrada por los awá meses después, muy delgada y debilitada, y regresó al pueblo donde aún vive.

\section{NUEVA NORMATIVA PARA VIEJOS PROBLEMAS}

Aquí actualizaremos las normativas más recientes publicadas relacionadas con pueblos indígenas aislados y contactados recientemente, además de las enumeradas por Vaz hasta 2011. En los últimos años, hemos observado que, gradualmente, el término contacto reciente (o recién contactado previamente) se ha insertado en algunos reglamentos internos del organismo indigenista.

Una de las normas internas más antiguas de FUNAI, aunque aún vigente, es la Instrucción Normativa (IN) Nº 01 / PRESI, de 29 de noviembre de 1995,

\footnotetext{
12 Nombre ficticio de una de las mujeres.
} 
que presenta las normas que rigen el ingreso a tierras indígenas con el propósito de desarrollar la investigación científica. En el artículo 9, solo se mencionan los pueblos indígenas aislados y no aquellos en contacto reciente. De manera desactualizada, destaca un flujo administrativo del proceso con el ex DII, que fue reemplazado por el CGIIRC.

El Reglamento Interno vigente de FUNAI (Portaria ${ }^{13} \mathrm{~N}^{\circ} 666$ / PRES, de 17 de julio de 2017) coloca el ingreso a tierras indígenas como una de las atribuciones de las coordinaciones internas de la CGIIRC - la COPIRC, la COPLII y las coordinaciones de los FPE.

Si bien la Instrucción Normativa (IN) N 01 / PRESI, de 29 de noviembre de 1995 se refiere a la admisión con fines científicos, la Portaria $N^{\circ} 177$ / PRES, de 16 de febrero de 2006 regula el procedimiento administrativo para el ingreso de personas a tierras indígenas para el uso, adquisición o cesión de derechos de autor y derechos de imagen indígena. En este último, en el artículo 20, también se indica la participación de la Coordinación General de Indios Aislados con la Presidencia de FUNAI. Es interesante notar que la Portaria amplía su alcance más allá de los grupos considerados aislados a aquellos con poco contacto con los no indígenas, lo que estaría más cerca de lo que conocemos como contacto reciente.

El artículo 12, párrafo 1, ya menciona que «las contrapartidas e indemnizaciones que se deban a comunidades con poco o reciente contacto, o a colectividades indefinidas; y los recursos que no puedan aplicarse directamente a la comunidad indígena titular del derecho deben depositarse en la Renta del Patrimonio Indígena». Es decir, ahí ya usa el término contacto reciente.

Sería interesante que esta normativa fuera reformulada y actualizada de acuerdo con la estructura administrativa actual del organismo indígena y que tuviese en cuenta las especificidades de los PIRC, incorporando mecanismos de consulta recientes como el Protocolo de Consulta Yanomami y los resultados del Plan de Manejo Territorial y Ambiental - PGTA de la Tierra Indígena Zo'é, por ejemplo.

Otra Instrucción Normativa, la IN N 3 de 11 de junio de 2015, establece normas y lineamientos para las actividades con fines turísticos en tierras indígenas. El artículo 13 expone un flujo en el caso de turismo previsto en tierras indígenas con presencia de pueblos aislados o de contacto reciente ${ }^{14}$. Una información

13 Portaria es un término que podría traducirse como ordenanza, pero se mantiene a lo largo del texto el original en portugués por no tener una traducción exacta en otros sistemas legales.

14 En Brasil encontramos una iniciativa de turismo comunitario de un grupo de contacto reciente. Se trata del proyecto «Yaripo: ecoturismo yanomami», de los grupos yanomamis que viven 
técnica debe ser emitida por el CGIIRC, acompañada de una declaración preliminar del correspondiente Frente de Protección Etnoambiental ${ }^{15}$.

Existe, aún más reciente, la Instrucción Normativa 01 del 13 de mayo de 2016, que «establece normas y lineamientos para la atención de la FUNAI, la promoción y protección de los derechos de la niñez y juventud indígena y la realización del derecho a la convivencia familiar y comunitaria». El artículo 5 establece en su único párrafo que los casos de contacto reciente o pueblos aislados deben ser reportados a la Dirección de Protección al Desarrollo Sostenible - DPDS y a la Dirección de Protección Territorial - DPT para su seguimiento y conocimiento. Esta atención especial a PIRC también aparece como una respuesta a demandas que involucran el secuestro de niños de estos pueblos.

Destacamos un importante avance en la formalización de la política con la publicación de la Portaria que crea el Programa Korubo (Portaria N ${ }^{\circ} 693$ / PRES, de 23/05/2019). El Programa Korubo es un «conjunto de iniciativas articuladas con el objetivo de proteger y promover los derechos del pueblo Korubo de contacto reciente, a través de la implementación de acciones que consideren sus especificidades sociales, físicas y culturales». Según el PPA, se prevé la formalización de seis programas más. Consideramos que el formato del programa es muy interesante y productivo. Más que un tipo de acción, es una metodología.

Este reglamento interno de FUNAI trata varios temas fundamentales para los pueblos indígenas de reciente contacto. En el país, tenemos los PIRC mencionados de manera discreta en la Política Nacional de Gestión Territorial y Ambiental de Tierras Indígenas - PNGATI. Según el capítulo II «Lineamientos y objetivos», artículo 3, ítem VII, «la protección territorial y ambiental de las tierras ocupadas por pueblos indígenas aislados y de contacto reciente» es uno de los lineamientos de PNGATI. También hay otra mención en el artículo 4, eje 3 sobre «la participación de FUNAI en los consejos de manejo de unidades de conservación adyacentes a tierras con presencia de indígenas aislados o de

en la región de Maturacá. El plan de visitas (AYRCA y AMYK, 2019), aprobado en 2019, fue propuesto por la Asociación Yanomami del Río Cauaburis y Afluentes - AYRCA y la Asociación de Mujeres Indígenas Kumirayoma - AMYK. El documento forma parte del PGTA yanomami y ye'kuana y combina varios objetivos: generación de ingresos; protección territorial; actividad alternativa a la minería de oro; fortalecer la cultura yanomami, y asegurar el protagonismo de los yanomami a través de las asociaciones AYRCA y Kumirayoma.

15 El IN también indica que la «confirmación de la presencia de indígenas aislados en la zona afectada por el Plan de Visitas» (artículo 23, inciso VI) puede ser una de las causas de suspensión o revocación del Plan de Visitas. Según el artículo 28, para visitar estos territorios se podrán tomar medidas de protección adicionales indicadas por el CGIIRC y los FPE. 
contacto reciente». Esta participación se ha producido en el directorio de PARNA Pico da Neblina, por ejemplo. Pero no es significativo dadas las posibilidades de interfaz que podrían ocurrir entre PNGATI y la política para PIRC, que deberían ser exploradas más a fondo.

Sin embargo, en este mismo tema, es necesario mencionar la elaboración de los primeros PGTA elaborados con el PIRC, en este caso los yanomami y los zo'é. Todas las asociaciones fueron esenciales para el trabajo. Ambos fueron procesos surgidos de acciones intersectoriales, articuladas entre el gobierno y la sociedad civil, participación activa de los pueblos involucrados y posibilitados con recursos del Proyecto Vida Sustentable del Fondo Amazonia. Sus metodologías y productos finales son creativos y realmente pueden contribuir al bienestar de estos pueblos. La construcción del PGTA de la TI Zo'é fue el resultado de una alianza entre el Instituto de Investigación y Capacitación Indígena - Iepé y el Frente de Protección Etnoambiental Cuminapanema - FPEC de FUNAI. Entre 2016 y 2019 se llevaron a cabo actividades que involucraron un importante conjunto de actividades colaborativas con los zo'é, como las encuestas socioambientales; actividades de encuestas en las aldeas y el uso de los recursos naturales; talleres de elaboración de mapas; expediciones territoriales de reconocimiento y vigilancia; expediciones de inspección y monitoreo dentro de los límites de TI; proceso de alfabetización, sistematización del vocabulario y categorías zo'é, viajes e intercambios, entre otros.

Se pusieron a disposición nuevas tecnologías de comunicación en el contexto del proyecto, como sistemas radiofónicos para todos los pueblos, lo que permitió un mayor diálogo entre ellos, dando más autonomía a las comunidades.

Utilizando una metodología de discusión adecuada a las especificidades de estas personas, los zo'é manifestaron sus prácticas de gestión territorial y desarrollaron pautas progresivamente para la gestión socioambiental de la TI Zo'é, así como la consolidación de los mecanismos de gobernanza (Iepe, 2019). Según Gallois, el PGTA «permitió a los Zo’é consolidar una nueva posición en relación con la defensa de sus propios intereses» (Gallois, 2020, p. 110). En otras palabras, el proceso de elaboración de un PGTA fue el locus de producción de nuevas perspectivas.

También se produjo una experiencia interesante en la elaboración del PGTA con los pueblos yanomami y ye'kwana. El desafío de la construcción fue enorme, considerando que es la tierra indígena más grande de Brasil con una gran diversidad sociocultural, con más de 27000 habitantes y seis idiomas diferentes. Como resultado, entre 2018 y 2019 se creó el Protocolo de Consulta Yanomami 
y Ye'kwana (Hutukara, 2019), una importante herramienta para el diálogo y la lucha por los derechos de estos pueblos. También se elaboraron y sistematizaron lineamientos para iniciativas existentes que se encontraban dispersas. Así, «toda propuesta, obra o proyecto en TIY debe seguir los lineamientos redactados en la PGTA, los cuales están subordinados a una estructura de gobierno interno con sus propias reglas» (Vieira, 2020, p. 103).

Los PGTA zo'é y yanomami son experiencias que apuntan a otros caminos y fueron exitosas, a nuestro juicio, ya que contaron con un abanico de iniciativas de diversa índole, suficientes recursos humanos y económicos y, sobre todo, una amplia participación de los pueblos involucrados.

A lo largo de los años, se formularon otras regulaciones más amplias y específicas para los PIRC. Destacamos aquí la poco conocida Parecer ${ }^{16} 09$ / CEB / CNE del 7 de octubre de 2015, del Consejo Nacional de Educación sobre procesos educativos para pueblos indígenas de contacto reciente.

El Parecer destaca varios aspectos y lineamientos sobre educación para los PIRC $^{17}$, ampliando la noción de «educación» en sí misma, aportando nuevos enfoques y configuraciones que van más allá de la educación formal y escolar, que propone un pasaje más adecuado hacia «procesos educativos comunitarios». El Parecer 09 debería ser más utilizada como parámetro por las organizaciones gubernamentales y de la sociedad civil para la elaboración de proyectos educativos comunitarios con PIRC. Observamos que esta no es una norma muy conocida y tampoco utilizada.

Algunos PIRC acceden a la educación escolar formal, como awá, avá canoeiro, yanomami, juma y hupdä'h y yuhupdeh, por ejemplo. Pero, para la mayoría de los pueblos, este tipo de educación no se ajusta a sus especificidades y ha sido durante mucho tiempo la puerta de entrada de amenazas a los PIRC como misioneros

16 Parecer puede ser traducido como opinión, pero se mantiene el original a lo largo del texto por ser un término administrativo sin traducción exacta en otros sistemas legales.

17 El Parecer menciona espacios educativos, acceso al conocimiento, infraestructura física específica para la escuela, proyectos educativos vinculados con los derechos territoriales, educación, salud, cultura y asistencia social; organización de actividades educativas; talleres, presentaciones, debates, intercambios interculturales, visitas focalizadas a ciudades y otras comunidades indígenas; el uso de la Lengua Portuguesa y las Matemáticas como herramientas útiles para la relación de estos pueblos con la sociedad nacional y con los ámbitos del Estado brasileño; elaboración, publicación y distribución de material didáctico y didáctico específico en diversos soportes y medios, y la promoción del conocimiento y la reflexión crítica sobre el «mundo de los blancos», de forma autónoma y no colonizada. 
fundamentalistas ${ }^{18}$, por ejemplo. Al igual como ocurrió con otros pueblos indígenas, hemos visto situaciones donde la escuela ha alterado calendarios, flujos y formas de vida, llevando a los docentes de los PIRC a «monetizarlos», intensificando sus desplazamientos a las ciudades para «resolver la burocracia» $\mathrm{y}$ pasando por diversas situaciones de vulnerabilidad.

La Portaria Conjunta del Ministerio de Salud / FUNAI N 4.094, del 20 de diciembre de 2018 , que «define principios, directrices y estrategias para la atención de la salud de los pueblos indígenas aislados y de contacto reciente», fue quizá la normativa más importante publicada recientemente.

Su gestación se inició en 2013, con la creación de un Grupo de Trabajo Interministerial (GTI) ${ }^{19}$ con el propósito de desarrollar lineamientos y estrategias de acción en salud para pueblos indígenas aislados y de contacto reciente, así como un Plan de Contingencia de salud para situaciones de contacto con pueblos aislados y brotes epidémicos en grupos de contacto reciente (Jabur, 2017).

Desde entonces, se ha generado un cúmulo de discusiones entre CGIIRC / FUNAI y SESAI a través de documentos técnicos; análisis médicos, jurídicos y antropológicos; numerosas reuniones presenciales; realización de seminarios ${ }^{20}$ que culminaron con la elaboración de la citada Portaria. Vinculado con esto, la experiencia práctica de las dos instituciones en el manejo de los contactos que tuvieron lugar entre 2014 y 2015 contribuyó con numerosos aportes técnicos (Rodrigues, 2020, p. 43). En todo este proceso fue fundamental la colaboración de especialistas como indigenistas, sertanistas, médicos, antropólogos, académicos, organizaciones indigenistas de la sociedad civil y los propios pueblos indígenas.

Finalmente, cinco años después, en diciembre de 2018, fue publicada la Portaria Conjunta Ministerio de Salud / FUNAI N 4.094, el primer reglamento que aborda de manera más contundente uno de los temas cruciales para el bienestar actual y la supervivencia del PIRC. Antes, la atención de salud de los PIRC solo se mencionaba discretamente en la Política Nacional de Atención de Salud Indígena de Brasil - PNASI, como una «situación especial» (FUNASA, 2002, p. 19 y Jabur, 2017).

18 Históricamente, algunas misiones religiosas fundamentalistas se pusieron en contacto con los pueblos indígenas con el propósito de evangelizar. Una de las puertas de enlace puede ser proyectos con un carácter «pseudoeducativo».

19 Creada por la Portaria Interministerial $N^{\circ} 171$, de 06/02/2013.

20 Uno de estos eventos, el taller sobre metodologías de atención en salud, protección y promoción de los derechos de los pueblos indígenas aislados y contacto reciente en Brasil, fue promovido por la Organización del Tratado de Cooperación Amazónica - OTCA, FUNAI y SESAI en noviembre de 2013. 
La Portaria es igualmente importante por presentar los principios, lineamientos y estrategias que deben regir «la acción conjunta de la Secretaría Especial de Salud Indígena - SESAI / MS y la Fundación Nacional del Indio - FUNAI en la planificación, coordinación, ejecución, seguimiento y evaluación de acciones para la atención de salud de Pueblos Indígenas Aislados y de Contactos Reciente» (artículo 1).

El tercer punto fuerte de la Portaria es que reconoce que «las situaciones de contacto, brotes y epidemias que involucran a PIRC deben ser consideradas una emergencia de salud y requieren medidas inmediatas y adecuadas para reducir la morbimortalidad asociada con la ruptura del aislamiento» (artículo 4). Esta pauta es fundamental para que las medidas se tomen lo más rápidamente posible y con los recursos necesarios que requieren las situaciones de contacto.

A pesar de los grandes avances que trajo la Portaria - más aún en un momento de pandemia - , hasta el momento no se ha cumplido con la recomendación contenida en el artículo $22^{21}$. Es decir, aún no se ha publicado el documento rector para la elaboración de Planes de Contingencia - PC y el establecimiento de protocolos para la atención de la salud de los pueblos aislados y de contacto reciente. Esta ausencia provocó algunas complicaciones en la elaboración de los planes de contingencia para combatir el coronavirus entre los PIRC.

Analizando los PCs disponibles ${ }^{22}$, nos damos cuenta de que cada Distrito Sanitario Especial Indígena - DSEI eligió un modelo diferente para su elaboración. La minoría, especialmente al inicio de la pandemia, utilizó las pautas, principios y elementos esenciales que deben contener los $\mathrm{PC}^{23}$, como se indica en el artículo 8 de la Portaria.

Otros DSEI activaron el modelo del Plan Nacional de Contingencia de la SESAI para elaborar su PC específico en el combate a la COVID-19 (SESAI, 2020). En general, fueron planes más genéricos, que no apuntaban a mecanismos prácticos, acciones interinstitucionales ni protocolos que atiendan las especificidades culturales y sociales de cada pueblo. También se pudo observar que algunos

21 El plazo para el cumplimiento de esa determinación era de 180 días y se venció en junio de 2019.

22 Los PC de los DSEI están disponibles en el link: https://drive.google.com/drive/u/0/ folders/1ti4y0weLDsJYdL-R3r2FuxDf8XWDn2O

23 Los elementos mínimos del PC, según la ordenanza, son: (i) atribuciones y competencias; (ii) flujos de servicios y comunicaciones; (iii) recursos materiales y humanos; (iv) protocolos de cuarentena y vigilancia sanitaria; (v) acciones de inmunización; (vi) los procedimientos de remoción; (vii) registros de asistencia y notificación; (viii) los protocolos de conducta del equipo, y (ix) los posibles escenarios. 
planes no habían sido elaborados de manera conjunta entre SESAI y FUNAI, como se especifica en el artículo 9 de la Portaria Conjunta.

La inexistencia e inconsistencia de algunos PC fue alertada por el Observatorio de los Derechos Humanos de los Pueblos Indígenas Aislados y de Contacto Reciente - OPI justo al inicio de la pandemia (OPI, 2020b). Paulatinamente, algunos PC fueron reelaborados, sin embargo, no todos incluyen aún los elementos básicos indicados en la Portaria Conjunta y siguen siendo genéricos, no adecuados a la realidad de algunos PIRC.

Durante la nueva pandemia de coronavirus en 2020, la Portaria Conjunta fue ampliamente utilizada y citada en documentos legales, manifiestos y estudios, entre otros. El mayor ejemplo es el ADPF (Incumplimiento de Precepto Fundamental, por sus siglas en portugués) que fue solicitado por la Articulación de Pueblos Indígenas de Brasil - APIB con partidos políticos de oposición (PSB, PSOL, PCdoB, Rede, PT y PDT). Es importante destacar las dos principales medidas establecidas para los PIRC en la decisión del ministro Roberto Barroso del 8 de julio de 202024: (i) establecimiento de barreras sanitarias para evitar el ingreso de invasores a territorios habitados por pueblos indígenas aislados y contacto reciente; (ii) activación de la Sala Situacional, según artículo 12 de la Portaria Conjunta $\mathrm{N}^{\circ} 4.094$ / 2018, es decir, «para apoyar la toma de decisiones de los gestores y la acción de los equipos locales ante el establecimiento de situaciones de contacto, brotes o epidemias que involucren a Pueblos Indígenas Aislados y de contacto reciente» (Brasil , 2018; APIB, 2020; Araújo Junior, 2020).

El ADPF fue quizás la acción más emblemática e importante emprendida por los pueblos indígenas en Brasil en las últimas décadas. "A más de 30 años de la promulgación de la Constitución, es la primera vez que los pueblos indígenas acuden a la Corte Suprema, en su propio nombre, defendiendo su propio derecho y a través de sus propios abogados, proponiendo una acción de fuero constitucional» (Eloy, 2020).

Los PIRC también fueron contemplados en el artículo 1, Párrafo 1, de la Ley $\mathrm{N}^{\circ} 14.021$, de 7 de julio de 2020, que «establece medidas de protección social para prevenir el contagio y la propagación de la COVID-19 en territorios indígenas; crea el Plan de Emergencia para Combatir la COVID-19 en Territorios Indígenas $[\ldots] »$.

24 También está en su decisión que la Unión elabore un Plan General de Lucha contra la COVID-19 para los Pueblos Indígenas. Hasta el momento, se han presentado tres versiones del plan, pero el ministro Barroso las consideró «genéricas y vagas» (ver http://www.stf.jus.br/portal/cms/ verNoticiaDetalhe.asp?idConteudo=453860). 
El Capítulo IV está íntegramente dedicado al tema de los PIRC y presenta las medidas a tomar por la Unión: elaboración de planes de contingencia para situaciones de contacto reconocidas por FUNAI; elaboración, dentro de los diez días, de planes de contingencia para brotes y epidemias específicos para cada pueblos de contacto reciente; cuarentena obligatoria; suspensión de actividades en regiones cercanas a las ocupadas por pueblos aislados, y disponibilidad inmediata de pruebas diagnósticas COVID-19 y equipos de protección personal para todos los DSEI que operan en áreas donde existen registros oficiales de pueblos indígenas aislados o presencia de pueblos indígenas de contacto reciente (Brasil, 2020).

El artículo 13 prohíbe el ingreso de terceros a áreas con presencia confirmada de pueblos indígenas aislados, excepto aquellos autorizados por FUNAI o agentes públicos que sigan los lineamientos de la Organización Mundial de la Salud. Sin embargo, el $\S 1$ del mismo artículo casi «selló» la permanencia de las misiones religiosas que ya se encuentran en estos territorios mientras gocen de buena salud ${ }^{25}$. Esta sección está sujeta a la Acción Directa de Inconstitucionalidad - ADI N ${ }^{\circ} 6.622$, propuesta por la Articulación de los Pueblos Indígenas de Brasil - APIB y por el Partido de los Trabajadores - PT. La acción contó con el apoyo de indigenistas y especialistas en el tema (Pontes et al., 2021 y Vaz et al., 2021) y está en curso.

Con base en nuestras décadas de experiencia laboral en el campo, a favor de los derechos de los pueblos indígenas, tenemos un claro entendimiento de los efectos nocivos sobre los pueblos indígenas aislados que se producirán a partir de la aplicación del párrafo 1 del artículo 13 de la Ley 14.021 / 2020. Contrario a lo señalado en el caput, la presencia de invasores - personas extrañas (incluidos misioneros) en tierras indígenas donde viven pueblos indígenas aislados debe estar totalmente prohibida, salvo en el caso de servidores públicos y socios en estricto cumplimiento de las atribuciones reguladas por la política indígena o por los pueblos indígenas con los que tradicionalmente comparten los mismos territorios.

Otro gran avance en materia normativa fue la publicación de la Resolución $\mathrm{N}^{\circ}$ 44, de 10 de diciembre de 2020, del Consejo Nacional de Derechos Humanos - CNDH, que «establece principios, lineamientos y recomendaciones para garantizar los derechos humanos de los pueblos indígenas en aislamiento y contacto reciente, así como para la salvaguarda de la vida y el bienestar de estos pueblos»». A pesar de citar a los PIRC, la resolución está más dirigida a los pueblos indígenas

$25 \ll \S 1$ Las misiones de carácter religioso que ya se encuentran en comunidades indígenas deben ser evaluadas por el equipo de salud responsable y pueden quedar con la aprobación del médico responsable» (Brasil, 2020). 
aislados, incluso enfatizando que, «también se aplica, según corresponda, a los pueblos indígenas y / o segmentos de contacto reciente» (artículo 2). Esto enfatiza lo que mostramos anteriormente, la asociación entre contacto reciente y aislados.

La resolución también señala la necesidad de realizar discusiones con la participación del Estado, las organizaciones indígenas y la sociedad civil para definir «estrategias de acción específica con estos pueblos, mejorando así la política pública dirigida a los pueblos de contacto reciente» (párrafo 2). Queda un largo camino por recorrer.

Ciertamente, más necesario que seguir avanzando en la elaboración de normativas es asegurar que sus medidas sean efectivamente implementadas en forma de movimientos prácticos que realmente promuevan los derechos de los PIRC. Para ello, las FPE deben fortalecerse con recursos financieros y humanos.

\section{Desafios}

En el contexto social, político, económico y epidemiológico actual, el mayor desafío para el PIRC es literalmente sobrevivir. Sus tierras son invadidas, degradadas, deforestadas o quemadas.

Las familias se están infectando con COVID-19 u otras enfermedades, y muchos de ellos mueren. Durante la pandemia, los PIRC activaron sus propias estrategias para evitar epidemias, pero muchos se enfrentaron a invasores y otros factores. En el caso de los yanomami, la malaria obligó a algunos grupos a regresar de un aislamiento temporal a los centros de salud para buscar tratamiento.

Con la excepción de los zo'é, akuntsu, kanoe, zo'e, korubo y ava canoeiro (de TI Avá Canoeiro), todos los demás PIRC — es decir, yanomami (Machado et al., 2020), awá, suruwaha, juma, arara (TI Cachoeira Seca) (Schwarzenholz, 2020), enawenê-nawê, waimiri-atroari, hupdäh, yuhupdeh, araweté, parakanã (TI Apyterewa) y Tsohom-Djapa (Steffanie, 2020), tenían al menos un individuo contaminado por COVID-19. No tenemos información sobre el pueblo xinane o sobre los pirahã. Hasta el momento, tristemente, la COVID-19 se ha cobrado varias vidas y, entre ellas, Ariká, el último hombre del pueblo juma (OPI, COIAB y APIB, 2021).

Las situaciones que más merecen atención son las que ocurren en los TI de la región del Xingu Medio y en la TI Yanomami (Machado et al., 2020). Las vacunas comienzan a ser aplicadas a paso lento y son la solución más efectiva para la protección de estos pueblos, ya que hubo gran dificultad de los órganos competentes en aplicar medidas rápidas y eficientes para el combate al coronavirus entre los PIRC y para los pueblos indígenas de manera general. 
Otro gran desafío estructural para garantizar los derechos de los pueblos indígenas en general, pero especialmente de los pueblos de reciente contacto, es superar el desconocimiento que la sociedad brasileña y el propio Estado tienen sobre el tema (Jabur, 2016). Es necesario intensificar los estudios, discusiones, foros y debates sobre los PIRC, para que la categorización de los PIRC sea más clara, reduciendo el desconocimiento de esta categoría administrativa y sus consecuentes imágenes erróneas.

Sin embargo, es notorio que, paulatinamente, el término de contacto reciente ha sido cada vez más mencionado en manifestaciones públicas, estudios, producciones académicas, piezas legales e informes. Sin embargo, como enumeramos a lo largo del artículo, notamos que las producciones sobre PIRC están reducidas o ligadas al tema de indígenas aislados ${ }^{26}$. La política para PIRC está «a mitad de camino» y tiene un largo trecho por recorrer para consolidarse.

Es deseable que cada vez haya más acciones transversales, intersectoriales e interinstitucionales organizadas. Asimismo, es necesario seguir estableciendo alianzas e iniciativas, formales o no, pequeñas, medianas y grandes, con instituciones gubernamentales y no gubernamentales para la consolidación e implementación de la política.

La gran mayoría de PIRC no participa en foros de control social. Así, sus demandas son poco o mal incluidas en instancias como el Consejo Distrital de Salud Indígena - CONDISI, por ejemplo. Hay una serie de dificultades en la participación debido a problemas lingüísticos o culturales y barreras metodológicas, como el tipo de lenguaje técnico que se usa comúnmente en las reuniones. En general, las formas de representación política de los pueblos indígenas de contacto reciente no son reconocibles por el Estado, ya que, en general, no se representan a sí mismos a través de asociaciones y organizaciones formales ni mediante un liderazgo central.

Finalmente, creemos que, para una consolidación paulatina pero real de la política, es necesario que los propios PIRC sean consultados y participen en su construcción de manera calificada, en foros adecuados y acordes con sus formas de organización social y cultural.

26 Los trabajos que discuten la condición de «aislamiento» son mucho más numerosos, como en Gallois (1994); Gow (2011); Forline y Pozzobon (2006); Albert (2011); Otávio y Azanha (2009); Shepard (2016b); Cabral (2016); Amorim y Count (2011); Amorim (2017); Amorim y Yamada (2016); Pereira (2014); Vaz (2011); Huertas (2010); Silva (2017), Ricardo y Gongora (2019); Cangussu (2021), entre otros. 


\section{REFERENCIAS}

ACNUDH (Oficina del Alto Comisionado de las Naciones Unidas para los Derechos Humanos) (2012). Directrices de protección para los pueblos indígenas en aislamiento y en contacto inicial de la Región Amazónica, el Gran Chaco y la Región Oriental de Paraguay. Ginebra: ONU.

Albert, B. y Oliveira, M. W. (2011). Novos «isolados» ou antigos resistentes? En C. A, Ricardo (ed.), Povos Indígenas no Brasil: 2006/2010 (pp. 5-8). São Paulo: Instituto Socioambiental.

Amorim, F. (2016). Povos indígenas isolados no Brasil e a política indigenista desenvolvida para efetivação de seus direitos: avanços, caminhos e ameaças. Revista Brasileira de Linguística Antropológica, 8(2), UnB. https://doi.org/10.26512/ rbla.v8i2.16298

Amorim, F. (2017). Nos tapiris Korubo: uma perspectiva indigenista das tensões e distensões Korubo (e Matis). Recuperado de https:/povosisolados.com/2017/06/18/ nos-tapiris-korubo-uma-perspectiva-indigenista-das-tensoes-e-distensoeskorubo-e-matis/.

Amorim, F. (2018). O papel dos povos indígenas isolados na efetivação de seus direitos: apontamentos para o reconhecimento de suas estratégias de vida. Tipití: Journal of the Society for the Anthropology of Lowland South America, 16(1), Article 13, 149-157. Recuperado de https://digitalcommons.trinity.edu/tipiti/vol16/iss1/13

Amorim, F. y Yamada, É. (2016). Povos indígenas isolados: autonomia e aplicação do direito de consulta. Revista Brasileira de Linguística Antropológica, 8(2), 42-60. https://doi.org/10.26512/rbla.v8i2.16299

Amorim, F. y Conde, A. (2011). Situações de Contato e Isolamento no Vale do Javari. En C. A. Ricardo (ed.), Povos Indígenas no Brasil 2006/2010. São Paulo: Instituto Socioambiental.

Brasil (2020). Supremo Tribunal Federal. Ação direta de inconstitucionalidade $\mathrm{N}^{\circ}$ 709/ DF. Relator: Ministro Roberto Barroso. Recuperado de http:/www.stf.jus.br/ arquivo/cms/noticiaNoticiaStf/anexo/adpf709.pdf

Brasil (2020). Supremo Tribunal Federal. Ação direta de inconstitucionalidade $\mathrm{N}^{\circ}$ 6.622/DF. Relator: ministro Roberto Barroso. Recuperado de http://redir.stf.jus. br/estfvisualizadorpub/jsp/consultarprocessoeletronico/ConsultarProcessoEletronico.jsf? seqobjetoincidente $=6067929$

Araújo Junior, J. J. (2020). ADPF 709: a voz indígena contra o genocídio. Jota. Recuperado de https:/www.jota.info/opiniao-e-analise/artigos/adpf-709-a-vozindigena-contra-o-genocidio-08072020 
Brasil (1973). Presidência da República. Lei N 6.001, de 19 de dezembro de 1973. Dispõe sobre o Estatuto do Índio.

Brasil (2012). Presidência da República. Decreto $N^{\circ}$ 7.747, de 5 de junho de 2012. Institui a Política Nacional de Gestão Territorial e Ambiental de Terras Indígenas - PNGATI, e dá outras providências.

Brasil (2013). Portaria Interministerial $\mathrm{N}^{\circ} 171$, de 06/02/2013. Cria o grupo de trabalho para elaborar diretrizes e estratégias de ações em saúde para Povos Indígenas Isolados e de Recente Contato, bem como Plano de Contingência da Saúde para Situações de Contato com Povos Isolados e Surtos Epidêmicos em Grupos de Recente Contato.

Brasil (2018). Ministério da Saúde/Fundação Nacional do Índio. Portaria Conjunta Ministério da Saúde/Funai N 4.094, de 20 de dezembro de 2018. Define princípios, diretrizes e estratégias para a atenção à saúde dos povos indígenas isolados e de recente contato. Recuperado de https://www.in.gov.br/materia/-/asset_publisher/Kujrw0TZC2Mb/content/id/57220459

Brasil (2020). Presidência da República. Lei $N^{\circ}$ 14.021, de 7 de julho de 2020. Dispõe sobre medidas de proteção social para prevenção do contágio e da disseminação da COVID-19 nos territórios indígenas; cria o Plano Emergencial para Enfrentamento à COVID-19 nos territórios indígenas, estipula medidas de apoio às comunidades quilombolas, aos pescadores artesanais e aos demais povos e comunidades tradicionais para o enfrentamento à COVID-19; e altera a Lei $\mathrm{n}^{\circ}$ 8.080, de 19 de setembro de 1990, a fim de assegurar aporte de recursos adicionais nas situações emergenciais e de calamidade pública. Recuperado de http:// www.planalto.gov.br/ccivil_03/_ato2019-2022/2020/lei/L14021.htm

Conselho Nacional de Direitos Humanos - CNDH (2020). Resolução $\mathrm{N}^{\circ}$ 44, de 10 de dezembro de 2020. Recuperado de https://www.gov.br/participamaisbrasil/blob/baixar/2100\#: :text=Disp $\%$ C3\%B5e\%20sobre $\% 20$ princ $\%$ C $3 \%$ ADpios $\% 2$ C $\% 20$ diretrizes $\% 20$ e,e $\% 20$ bem $\% 2$ Destar $\% 20$ desses\%20povos.

Conselho Nacional de Educação - CNE (2015). Parecer 09/CEB/CNE em 07 de outubro de 2015. Orientações para a promoção do acesso de povos indígenas de recente contato a processos educacionais. Recuperado de http://portal.mec.gov.br/index. php?option=com_docman\&view=download\&alias=25211-parecer-cne-ceb00915-pdf\&Itemid=30192.

Cueva M., N. (2007). Una norma para la salud de los pueblos aislados y en contacto inicial. En B. Huertas Castillo (ed.), El derecho a la salud de los pueblos indígenas en aislamiento y en contacto inicial. Grupo Internacional de Trabajo sobre Asuntos Indígenas, el Instituto de Promoción de Estudios Sociales y la Fundación Biodiversidad. 
Davis, S. H. (1978). Vítimas do Milagre: O desenvolvimento e os índios do Brasil. Río de Janeiro: Zahar.

Eloy, L. H. (2020). ADPF no Supremo: Povos indígenas e o direito de existir. Mídia Ninja. Recuperado de https://midianinja.org/luizhenriqueeloy/adpf-709-nosupremo-povos-indigenas-e-o-direito-de-existir/

Forline, L. Y Pozzobon, J. (2006). O que será dos índios isolados ? En Amazônia além dos 500 anos. Belém: Museu Paraense Emilio Goeldi.

Freire, C. A. da R. (2008). Vida de Sertanista: a trajetória de Francisco Meirelles. Tellus, 8(14), 87-114. https://doi.org/10.20435/tellus.v0i14.151

FUNAI (1987). Documento Final do I Encontro de sertanistas.

FUNAI (1995). Instrução Normativa Nº 01/PRESI, de 29/novembro de 1995. Apresenta as normas que disciplinam o ingresso em Terras Indígenas com finalidade de desenvolver Pesquisa Científica. Recuperado de https://cep.ensp.fiocruz.br/sites/ default/files/instrucaonormativa001.pdf

FUNAI (2006). Portaria $N^{\circ}$ 177/ PRES, de 16 de fevereiro de 2006. Regulamenta o procedimento administrativo de entrada de pessoas em terras indígenas para o uso, aquisição e ou cessão de direitos autorais e de direitos de imagem indígenas. Recuperado de http://www.funai.gov.br/arquivos/arquivos1/conteudo/ouvidoria/ pdf/acesso-a-informacao/002-PORTARIA-177-2006-DireitoAutoral.pdf

FUNAI (2012). Portaria 1.733/PRES, de 27 de dezembro de 2012. Aprova o Regimento da FUNAI. Recuperado de http://www.editoramagister.com/ legis_24068367_PORTARIA_N_1733_DE_27_DE_DEZEMBRO_DE_2012. aspx\#: : text $=1 \% \mathrm{C} 2 \% \mathrm{BA} \% \overline{20} \% 2 \mathrm{D} \% 20 \mathrm{Fica} \% 20$ aprovado $\% 20 \mathrm{o} \% 20 \mathrm{Regi}-$ mento, $21 \% 20 \mathrm{de} \% 20$ dezembro\%20de\%201993.

FUNAI (2014a). Nota FUNAI. Recuperado de http:/www.funai.gov.br/index.php/ comunicacao/noticias/2884-nota-da-funai?highlight=WyJub3RhIiwiY29udGF0 byJd.

FUNAI (2014b). Grupo isolado Korubo faz contato. Recuperado de http://www.funai. gov.br/index.php/comunicacao/noticias/3040-grupo-isolado-korubo-faz-contato

FUNAI (2015a). Grupo isolado do povo Korubo é contatado no Amazonas. Recuperado de http://www.funai.gov.br/index.php/comunicacao/noticias/3529grupo-isolado-do-povo-korubo-e-contatado-no-amazonas

FUNAI (2015b) Instrução Normativa no 3 de 11 junho de 2015. Estabelece normas e diretrizes para as atividades de visitação com fins turísticos em Terras Indígenas. Recuperado de http://www.funai.gov.br/arquivos/conteudo/ascom/2015/doc/ jun-06/IN\%2003\%202015.pdf 
FUNAI (2016). Instrução Normativa $N^{\circ} 01$ de 13 de maio de 2016. Estabelece normas e diretrizes para a atenção da FUNAI, à promoção e proteção dos direitos das crianças e jovens indígenas e a efetivação do direito à convivência familiar e comunitária. Recuperado de https://www.in.gov.br/materia/-/asset_publisher/ Kujrw0TZC2Mb/content/id/22909492/do1-2016-05-17-instrucao-normativa-n1-de-13-de-maio-de-2016-22909237

FUNAI (2017). Portaria $N^{\circ}$ 666/PRES, de 17 de julho de 2017. Aprova o Regimento Interno da Fundação Nacional do Índio. Recuperado de https:/www.in.gov.br/ materia/-/asset_publisher/Kujrw0TZC2Mb/content/id/19183136/do1-2017-0719-portaria-n-666-de-17-de-julho-de-2017-19183102

FUNAI (2018). Relatório Final da Oficina «Diretrizes para o atendimento dos povos indígenas de recente contato: novas experiências, velhos desafios». Recuperado de http://redir.stf.jus.br/estfvisualizadorpub/jsp/consultarprocessoeletronico/ ConsultarProcessoEletronico.jsf?seqobjetoincidente $=5952986$

FUNAI (2019a). Povo Yanomami abre Pico da Neblina a visitantes. Recuperado de http://www.funai.gov.br/index.php/comunicacao/noticias/5676-povo-yanomami-abre-pico-da-neblina-a-visitantes

FUNAI (2019b). Portaria No 693/PRES, de 23 de maio de 2019. Cria o Programa Korubo. Recuperado de https://www.gov.br/funai/pt-br/arquivos/conteudo/ cogedi/pdf/boletim-de-servicos/2019/boletim-n-87-de-27052019.pdf

FUNAI (2020). Portaria $\mathrm{N}^{\circ}$ 419/PRES, de 17 de março de 2020. Estabelece medidas temporárias de prevenção à infecção e propagação do novo Coronavírus (COVID-19) no âmbito da Fundação Nacional do Índio - FUNAI. Recuperado de https:/www.in.gov.br/en/web/dou/-/portaria-n-419-de-17-demarco-de-2020-248805811

FUNAI (2021). Povos indígenas de recente contato. Recuperado de https:/www.gov. br/funai/pt-br/atuacao/povos-indigenas/povos-indigenas-isolados-e-de-recentecontato-2/povos-de-recente-contato-1

FUNASA (2002). Fundação Nacional de Saúde. Política Nacional de Atenção à Saúde dos Povos Indígenas. Brasília: Ministério da Saúde.

Gallois, D. T. (1994). De arredio a isolado: perspectivas de autonomia para os povos indígenas recém-contactados. En Luís Grupioni (org.), Índios no Brasil. Brasília: MEC.

Gallois, Dominique T. (2013). Essa incansável tradução (entrevista). Revista SextaFeira. São Paulo: Editora 34.

Gallois, D., Pedreira, H. P. da S. y Braga, L. V. (2020). Construindo um Plano de Gestão Territorial e Ambiental com os Zo'é. En L. D. B. Grupioni (org.), Em busca do bem viver. Experiências de elaboração de Planos de Gestão Territorial e Ambien- 
tal de Terras Indígenas. São Paulo: RCA. Recuperado de https://institutoiepe. org.br/wp-content/uploads/2021/02/2020-Livro-Em-busca-do-Bem-Viver.pdf

Garcia, U. F. (2010). Karawara: a caça e o mundo dos Awá-Guajá [tese de doutorado]. Programa de Pós-Graduação em Antropologia Social, Universidade de São Paulo, São Paulo.

Garcia, U. F. (2019). Pelas matas do Pindaré: imagens do isolamento Awa Guajá. En Fany R. y M. F. Gongora (orgs.), Cercos e resistências: povos indígenas isolados na Amazônia brasileira. São Paulo: Instituto Socioambiental.

Gil, Laura Pérez (2019). No limite da existência: o povo do Xinan. En F. Ricardo y M. F. Gongora (orgs.), Cercos e resistências: povos indígenas isolados na Amazônia brasileira. São Paulo: Instituto Socioambiental.

Gow, P. (2011). «Me deixa em paz!». Um relato etnográfico preliminar sobre o isolamento voluntário dos Mashco. Revista de Antropologia, São Paulo, USP, 54(1).

Huertas C., B. (eds.) (2007). El derecho a la salud de los pueblos indígenas en aislamiento y en contacto inicial. IWGIA, Instituto de Promoción de Estudios Sociales e Fundación Biodiversidad.

Hutukara (2019). Yanomami Yama Kixë, Ye'kwana Pëxë, Yëmakamayotima Protocolo de Consultar Siki. Protocolo de Consulta Yanomami e Ye'kwana. São Paulo: RCA, ISA, FUNAI.

IEPE/FUNAI (2019). Jo’e rekoha bokituteha ram. Planejando como vamos continuar vivendo bem no futuro. Plano de Gestão Territorial e Ambiental da TI Zo’é. São Paulo: Iepé e FUNAI.

Jabur, C (2016). Prefácio. Revista Brasileira de Linguística Antropológica, 8(2), 17-18. https://doi.org/10.26512/rbla.v8i2.16297

Jabur, C (2017). Saúde para Povos Indígenas Isolados e de Recente Contato. Box. En C. A. Ricardo y F. Ricardo (orgs.), Povos Indígenas no Brasil (2011-2016). São Paulo: Instituto Socioambiental.

Lima, A. C. de S. (1995). O Grande Cerco de Paz: poder tutelar, indianidade e formação do Estado no Brasil. Petrópolis: Vozes.

Machado, A, M., Weis, B,, Jabra, D, Yanomami, D, V. K., Gongora, M, F., Senlle, M, G., Rocha, M, T. y Martins, M, S. (2020). Xawara. Rastros da COVID-19 na Terra Indigena Yanomami e a omissão do estado. São Paulo: Instituto Socioambiental.

Magalhães, D. de (1943). Normas sociológicas para o aproveitamento do índio organizada pelo Gal. Cândido Mariano da Silva Rondo. En Rondon - uma relíquia da pátria.. Manaus. 
Magalhães, M. y Maxikôa A. G. (2017). Narrativa de Maxikôa sobre o retorno de Itapiry à aldeia após sua fuga com Marjuá (mimeo).

Matos, B. de A., Pereira, B., Ribeiro Santana, C., Amorim, F., do Val Santos, L. L. C. y Cravo de Oliveira, L. (2021). Violações dos direitos à saúde dos povos indígenas isolados e de recente contato no contexto da pandemia de COVID-19 no Brasil. Mundo Amazónico, 12(1), 106-138. https://doi.org/10.15446/ma.v12n1.88677

Meirelles, J. C. (2017). Uma boroca esquecida, uma boroca devolvida e um contato. Recuperado de https://www.facebook.com/jose.meirelles.509/ posts/668562773331199

Octavio, C. y Azanha, G. (2009). Isolados. Algumas questões para reflexão. São Paulo: Centro de Trabalho Indigenista.

Opi (2020a). Informe OPI N 1 do Observatório de Direitos Humanos dos Povos Indígenas Isolados e de Recente Contato. Povos Indígenas Isolados no Brasil. Resistência política pela autodeterminação. Recuperado de https:// povosisolados.com/2020/02/11/informe-observatorio-opi-n-01-02-2020-povosindigenas-isolados-no-brasil-resistencia-politica-pela-autodeterminacao/

Opi (2020b). Informe OPI n ${ }^{\circ}$ 2. A ameaça do COVID-19 e o risco de genocídio dos povos indígenas isolados e de recente contato. Recuperado de https://povosisolados. com/2020/05/14/informe-opi-n-2-a-ameaca-do-covid-19-e-o-risco-de-genocidio-dos-piirc/

Opi, COIAB y APIB (2021). A devastadora e irreparável morte de Aruká Juma. Recuperado de https://povosisolados.com/2021/02/17/a-devastadora-e-irreparavel-morte-de-aruka-juma/

Otto, R. (2017). Outra vez, me deixa em paz!: crônicas de um desencontro tupi-guarani no Maranhão. Revista de Antropologia da UFSCar, 9(1), jan./jun. 2017. https:// doi.org/10.52426/rau.v9i1.181

Pereira, A. V. (2018). Demarcando vestígios: definindo (o território de) indígenas em isolamento voluntário na Terra Indígena Massaco [dissertação de Mestrado]. Programa de Pós-Graduação em de Antropologia Social, Universidade Federal de São Carlos.

Pontes, A. L. de M., Coelho, C. de C., Rodrigues, D. A., Simões, E. L. J., Albertoni, L. I., Basta, P. C., Segalla, S. B., Andrade, S. L., Grupo de Interesse Especial em Saúde Indígena da Sociedade Brasileira de Medicina de Família e Comunidade (2021). Carta à APIB. Recuperado de http://redir.stf.jus.br/estfvisualizadorpub/jsp/consultarprocessoeletronico/ConsultarProcessoEletronico. jsf? seqobjetoincidente $=6067929$

Ramos, A. R. (1995). O índio hiper-real. Revista Brasileira de Ciências Sociais, 10(28). São Paulo. 
Reis, R. A. C. y Albertoni, L. (2017). Questões epidemiológicas e desafios no atendimento aos chamados povos isolados. Uma experiência de contato com os Korubo. Amazônica: Revista Antropológica, 9(2), 809-831. https://doi.org/10.18542/ amazonica.v9i2.5676

Ribeiro, D. (1996 [1970]). Os índios e a civilização: a integração das populações indígenas no Brasil moderno. Río de Janeiro: Civilização Brasileira.

Ribeiro, F. A. (2020). Encontro Zo'é nas Guianas [tese de doutorado]. Programa de Pós-Graduação em Antropologia Social, Universidade de São Paulo, São Paulo.

Ricardo, F. y Gongora, M. (orgs.) (2019). Cercos e Resistência: povos indigenas isolados na Amazônia brasileira. São Paulo: ISA.

Rodrigues, A. (2014). Awá-guajás estabelecem contato com índios isolados de reserva maranhense. Agência Brasil. Recuperado de https://agenciabrasil.ebc.com.br/ direitos-humanos/noticia/2014-12/awa-guajas-estabelecem-contato-com-indiosisolados-de-reserva

Rodrigues, D. (2013). Saúde e doença entre os Panará, Povo Indígena Amazônico de contato recente, 1975-2007 [tese de doutorado]. Programa de pós-graduação em Saúde Coletiva, Universidade Federal de São Paulo/ Escola Paulista de Medicina.

Rodrigues, D. (2014). Marco Estratégico para Proteção dos Povos Indígenas em Isolamento Voluntário e Contacto Inicial. Proteção e Assistência à Saúde dos Povos Indígenas Isolados e de Recente Contato no Brasil. Consultor Nacional de Saúde - Brasil. São Paulo: OTCA, março de 2014.

Rodrigues, D. (2019). Desafio da atenção à saúde dos povos isolados e de recente contato. En F. Ricardo y M. F. Gongora (orgs.), Cercos e resistências: povos indígenas isolados na Amazônia brasileira. São Paulo: Instituto Socioambiental.

Rodrigues, D., Mendonça, S. B. M. de y Albertoni, L. (2020). Antes sós do que mal acompanhados: contato e contágio com povos indígenas isolados e de recente contato no Brasil e desafios para sua proteção e assistência à saúde. Saúde Soc. São Paulo, 29(3), e200348. https://doi.org/10.1590/s0104-12902020200348

Santos, M. dos y Mendez, A. N. (2007). El trabajo de la FUNAI. En A. E. Parellada (ed.), Pueblos indigenas en aislamiento voluntario y contacto inicial en la Amazonía y el Gran Chaco (pp. 200-209). Copenhague: IWGIA.

Schmidt, S. (2020). Indígenas de recente contato do Vale do Javari são contaminados pela COVID-19. Amazônia Real. Recuperado de https://amazoniareal.com. br/indigenas-de-recente-contato-do-vale-do-javari-sao-contaminados-pelacovid-19/ 
Schwarzenholz, P. (2020). Indígenas de recente contato do Pará são os «mais infectados» do país. Rede Pará. Recuperado de https://redepara.com.br/Noticia/213829/ indigenas-de-recente-contato-do-para-sao-os-mais-infectados-do-pais

SESAI (2020). Plano de Contingência Nacional para Infecção Humana pelo novo Coronavírus (COVID-19) em Povos Indígenas. Brasília/DF. Março de 2020. Recuperado de https:/portalarquivos2.saude.gov.br/images/pdf/2020/fevereiro/13/plano-contingencia-coronavírus-COVID19.pdf).

Shepard, G. (2016a). A década do contato. En C. A. Ricardo y F. Ricardo (orgs), Povos Indígenas no Brasil (2011-2016). São Paulo: Instituto Socioambiental.

Shepard, G. (2016b). Ceci N'est Pas un Contacte: the Fetishization of Isolated Indigenous People Along the Peru-Brazil Border. Tipiti: Journal of the Society the Anthropology of Lowland South America, 14(1), 131-134.

Silva, Juliana O. (2020). O isolamento é possível? O caso de um povo de recente contato do Vale do Javari. Cadernos de Campo, 29, 244-254. https://doi.org/10.11606/ issn.2316-9133.v29isuplp244-254

Silva, J. O., Marques, R. de B. (2020). «Emergência sanitária no Vale do Javari e a situação dos povos de recente contato diante da COVID-19». Observatório dos Direitos Humanos dos Povos Indígenas Isolados e de Recente Contato. Recuperado de https://povosisolados.com/2020/06/21/emergencia-sanitariano-vale-do-javari-ea-situacao-dos-povos-de-recente-contato-diante-da-covid-19/. Acesso: 21/06/20

Tavares, L. (2020). Vivendo no «vazio»-Relações entre os sobreviventes Kanoê e Akuntsú da Terra Indígena Rio Omerê (RO) [dissertação de Mestrado]. Programa de Pós-Graduação em Antropologia Social, Universidade de Brasília.

Torres, L. F. (2020). Estrategias indígenas y politicas públicas durante la pandemia del COVID-19 en la Amazonía peruana: el caso de Madre de Dios. Salsa Tipiti. Recuperado de https:/www.salsa-tipiti.org/covid-19/estrategias-indigenasypoliticas-publicas-durante-la-pandemia-del-covid-19-en-la-amazonia-peruanael-casode-madre-de-dios-5-18-20/. Acesso em 18/05/2020.

Valente, R. (2017). Os fuzis e as flechas: história de sangue e resistência indígena na ditadura. São Paulo: Companhia das Letras.

Valadão, V. 1996. Os índios ilhados do Igarapé Omerê. En C. A. Ricardo (ed.), Povos Indígenas no Brasil: 1991/1995 (pp. 545-549). São Paulo: Instituto Socioambiental.

Vargas da Silva, B. N. (2017). Territorialidade Korubo no Vale do Javari -AM [dissertação de Mestrado], Programa de Pós-Graduação Sociedade e Cultura na Amazônia (PPGSCA), Universidade Federal do Amazonas (UFAM) / Instituto de Ciências Humanas E LETRAS (ICHL). 
Vaz, A. (2008). Missão O veneno lento e letal dos Suruwahá. Recuperado de https:// docplayer.com.br/18972085-Missao-o-veneno-lento-e-letal-dos-suruwahajunho-de-2008-antenor-vaz-cgii-funai.html

Vaz, Antenor (2011). Isolados no Brasil. Política de Estado: Da tutela para a política de direitos - uma questão resolvida? Informe IWGIA, 10.

Vaz, A., Santos, A. J. dos, Bigio, E., Meirelles, J. C. dos R., Wellington Figueiredo, Santos, M. (2021). Carta à $A P I B$.

Vieira, M. A. E. de M. (2020). Plano de Gestão e Governança da Terra Indígena Yanomami. En L. D. B. Grupioni (org.), Em busca do bem viver. Experiências de elaboração de Planos de Gestão Territorial e Ambiental de Terras Indígenas. São Paulo: RCA. Em-busca-do-Bem-Viver. 